\title{
ANGLOPHONE LEGAL CULTURE AND GLOBALIZATION: STATE, CORPORATION, AND TECHNOLOGY
}

\author{
Joseph P. Garske
}

This paper sets forth a way to understand, how technology has enabled Anglophone legality to employ, both the structure of the state and the structure of the corporation in its project of globalization. The paper does so by comparing the origins, development, and fundamental differences between the two Western legal forms, Civil and Common. It describes Civil law as a philosophical system, and Common law as a collegial system. This comparative approach is used to explain how Civil law is assimilated to the state, and how its Anglophone counterpart holds a position of equal and independent predominance toward both state and corporation. It shows how pragmatic adaptability is an advantage for the English method in constructing a global legal culture.

Keywords: civil law, continental law, Roman law, common law, Anglophone law, legal culture, technology, printing press, transcendence, hegemony, postmodern, modern, corporation, state.

\section{Legal cultures}

To understand the role of Anglophone legal culture in the project of globalization, it is useful to return to the sixteenth and seventeenth centuries, a crucial time for the Western tradition of law. During this period, several elements converged that would have a decisive impact on how medieval legal practices eventually developed into their modern forms. In many ways, the project of globalization today marks a return to the origin of those traditions. Events from that early time provide a way to understand the legal basis of global governance being constructed in the present day.

When looking back to that period it is important to remember that every regimen of law is comprised of two essential parts: an adjudicative aspect, and an educative aspect. In the short term, a mode of governance might impose order by shear force. But, over time, establishing an atmosphere of stability and continuity, requires the public to understand legal authority in terms of the benefits it confers; the public must also be taught a habit of compliance. Combining the methods for bringing order to human life and shape to human thought forms the basis of a legal culture.

The modern Anglophone version of such a legal regimen began almost four hundred years ago. It was born during an age shaped by a dramatic technological revolution that took place across all of Latin Christendom. That signal event was precipitated by three great inventions: the maritime compass, gunpowder weapons, and the printing press. Each of these three innovations had a dramatic effect: The improved compass brought an increase in sea trade and enormous wealth, the new weaponry brought mass armies and catastrophic warfare, while mechanical publication brought a proliferation of knowledge and learning.

Journal of Globalization Studies, Vol. 10 No. 1, May 2019 72-86 DOI: $10.30884 /$ jogs/2019.01.05 
The impact of the new inventions coincided with the rise of a powerful new merchant class, and medieval institutions, long established in Christian Europe, were thrown into a protracted period of upheaval and conflict. The formerly unified legal culture of Christian Europe was shattered by internecine wars, finally breaking up into hostile enclaves. England, geographically detached, and with a tradition of centralized monarchy different from its Continental neighbors, began to grow more insular in its legal composition. A fundamental gulf would develop between Europe and England as emphatic as the ocean channel that separated them.

In fact, the way in which the two legal methods began to diverge at that time had a great deal to do with the new technology of print. It was not only important that books of law could now be produced in quantity and with exact uniformity. Equally important, with the innovation of moveable type, those books could be published in multiple European languages, just by changing the order of the characters. A legal treatise no longer needed to be published only in the universal language of Latin. Instead, it could be published in one of the many European vernaculars. With the new techniques, regional jurisdictions began to arise with their own books published, for example, in French, German, Italian - and English. The beginning of the breakup of Christendom into nation-states had begun.

Out of these effects there also arose new approaches to governance and new methods of legality. Some of the old forms of rule - the kingdom, parliament, court, nation, estate, and profession - survived, but usually in an altered version. Equally important, the two traditions of law began to take on their modern forms. One was the Continental, or Civil law, born out of the ancient Roman tradition and out of the European university. It came to be integral to the heritage of culture and learning that prevailed on the Continent. The other was the Common, or Anglophone, law that had originated in England as a guild system of trade. From these two strands of development two legal cultures would come to shape events of the entire modern world. Especially, the English language law would become important in the project of globalization taking place hundreds of years later, in the twenty first century.

\section{A Medieval Law}

Both the Civilian and Anglophone traditions were born nearly a thousand years ago, during the medieval period. Those remote origins help explain why the two legal methods began to diverge more dramatically at the beginning of the modern period, around 1500, and how fundamental differences shape the very divergent role of each legal regime in the world today. That story begins in the eleventh century: The Continental law originated with the founding of the university at Bologna, Italy in 1088. At that time, the university was a new type of institution, a place for the academic study of law. Eventually the European university would also become a location for the study of arts and sciences, the heritage of culture and learning in the West. Thus, over centuries the legal culture of Europe came to reflect the underlying tradition of values and ideals that prevailed among the educated public, and among the public generally.

By contrast, the Common law tradition began with the Norman Conquest of England in 1066. The absentee kings who would rule that kingdom employed a unique sys- 
tem of courts, presided over by appointed justices. Over time, the functionaries who did the mundane work of court procedure organized themselves into guilds - a method of fraternal commerce widely employed on the Continent. Ultimately, guild members were able to supplant the justices and, among themselves, administer the three Royal Courts of Justice in London. Such an arrangement worked well for the king, because the courts then operated at no expense to the Royal Treasury. Instead, the guildsmen were self-supporting, collecting the fees and gratuities they exacted from their clients.

Originally, their single purpose was to litigate matters of dispute between noble landholders. Land was important because it was the main form of wealth and the main source of revenue for the king. The court lawyers had been granted a monopoly of trade, and, like all guildsmen, they protected their exclusive privilege through particular forms of knowledge and technique, which were held secretly among themselves. There came to be universities in England, at Oxford and Cambridge, but the internal learning of the guilds had no necessary connection with what was studied at the university.

During the convulsive sixteenth and seventeenth centuries a merchant class - already, highly evolved on the Continent-began to develop in England as well, and officers of the Royal Courts began to litigate issues of both landed and monetary wealth. Moreover, as their legal acumen converged with the new financial interests, the jurisdiction of the guildsmen began to enlarge. Their authority eventually came to predominate in all the courts of England, including the High Court of Parliament and, finally, within the Monarchy itself.

From that time forward, there were at least three aspects of the Anglophone approach to law that distinguished it from its Continental counterpart. At its inception, and continuing to its most modern form, those aspects would be basic to its nature: First, it was a collegial system of law, anchored in the fellowship of its members and in the punitive authority wielded by its judges. Because its approach was fraternal and pragmatic, maintaining unity among its members was necessarily, the overriding premise of its work. Moreover, unlike the Civil law, which came to be taught at many universities, and in numerous languages - the cohesion of Anglophone law required that all its members speak English.

A second important aspect of the Common law lay in its essential purpose as a medieval guild of trade. Unsurprisingly, in the pattern of the time, that purpose was the enrichment of its members. Every type of guild provided either a product or a service; in the case of the law guilds, they provided law court proceedings. Like other guilds, from their inception, the fraternities of law worked to insure the perpetuation of their trade and the exclusion of unwanted competition. By these means they sought to protect their sources of income.

A third characteristic of the Common law was its independence, as a fellowship, in relation to other councils and orders of the King and his men. Because Norman England was ruled mostly by absentee monarchs, the Royal Courts quite naturally came to function without close oversight. Even though the guildsmen imposed the law of the realm, their collective purpose was not precisely the same as the purpose of that law. Instead, their purpose was to profit from transacting the procedures of that law. This and several other aspects of the guild fellowship-its closed assemblages, esoteric knowledge, and collectively, the astonishing wealth of its members - insured its independence. 
The three elements of collegiality, the incentive of profit, and a relative autonomy would survive even within modern structures of government, centuries later. Moreover, the Common lawyers would continue to manifest themselves as an independent fellowship, the guild of trade - a distinctly medieval construction. While at the same time, beginning in the seventeenth century, the Civil advocates began to wield their authority through the structure of the newly founded nation-state - a distinctly modern innovation. These two very different placings of the law, one distinct from, and one assimilated into the structure of government, illustrated a profound difference. Over time, the Common and Civil approaches would, each, prove to have both advantages and disadvantages.

Civil law could offer the advantage of being both understandable and predictable in matters of litigation. The work of the Civilians rested on well understood principles of rationality and clarity, and they followed the law laid down by enacted statute. However, the Common lawyers, because of their self-directed independence, had the advantage of adaptability in any situation, a basis of their remarkable longevity. In fact, the source of their legal innovation was different as well: if the independent scholar was the great incubus of Civil law progression, the independent judge shaped the developing features of Common law. Moreover, the judge, unlike the scholar, had the power to enforce his view.

\section{Two Structures}

Actually, it had been Romanist scholars on the Continent who had made dramatic advances in the workings of the law, especially during the time when new forms of government and commerce were being attempted. Many of their novel concepts and innovations were easily adopted by the pragmatic Common lawyers as well. There were no better examples of this opportune borrowing than two seventeenth century innovations, the nation-state and the corporation. Although both these legal entities had been originated by Civil law scholars, eventually, both would also become widely established within the English-speaking realm.

During the seventeenth century legal revolution taking place both in England and on the Continent, there was a search for new instruments of rule by law. Most frequently, these concerned methods for ordering relations of property and persons, both matters urgently important to those who governed. At the time, quite naturally, there was a reliance on old forms that were familiar and had, by experience, proven to be reliable. There was also a proliferation of scholarship, in an attempt to adapt two inherited legal traditions-the Roman Codes (following on the Jus Commune) and the Merchant Law (the Lex Mercatoria)-to fit the new circumstance. Out of this search were developed new techniques by which sovereign power could be exercised, controlled, delegated, and extended.

At the time, in both England and on the Continent, these emergent forms of administering and enforcing were not always clearly defined. Especially, for example, the difference between what in modern times would become a state, an estate, a corporation, a commonwealth, or a company, were not precisely distinguished from one another. In fact, in different contexts, each term might have a different meaning, while, in other situations, certain of these terms could be used almost interchangeably. These 
confusions were even more pronounced in English practice, because its jurisprudence was by nature both inexplicit and opaque.

In the Anglophone realm this lack of distinction can be seen in two well-known examples: one concerns the manner by which England was ruled from 1653 to 1659, under a form of government called The Commonwealth. It was a harsh militaristic and theocratic rule, but it had many of the standard features of a modern state. It held unquestioned authority over the land and people within its borders. It had a judiciary and a parliament, a means of taxation, and an army to fight wars and to quell domestic rebellion.

But in an era when the term sovereignty often meant virtual ownership, the Commonwealth also had many properties typical of the modern corporation. Its circle of leaders, including the Lord Protector, Oliver Cromwell, acted very much like the officers and proprietors of an enterprise for amassing property and wealth. Under The Commonwealth, tens of thousands of small free-hold farmers were driven from their lands and villagesholdings that, by right of tenure, had often been in the same families for generations. Whole regions were confiscated, their chapels, markets, and dwellings levelled, as the arable land was divided among members of the newly emergent ruling caste.

In the process, the mechanisms of this state structure produced the material benefits of a modern business conglomerate, and all was accomplished with scrupulous attention to the requirements of a newly propounded law. An enormous population of destitute and disenfranchised people were expelled from the countryside, reduced to abject poverty, and forced to live in the hovels and tenements of the city. Great landed estates were assembled out of what had once been many separate farmsteads. Over decades, the effects of these expulsions amounted to one of the great transfers of wealth and property in English history.

In contrast to government under The Commonwealth, the British East India Company, founded in 1600, was expected to operate very much like a modern multi-national corporation. It was the creature of its stockholders, and was intended to exploit the servile labor and seemingly inexhaustible resources of distant regions, especially India. In fact, for more than two centuries, the East India Company became the conduit by which wealth was extracted from the Indian sub-continent. What had been an empire of ancient and fabulous opulence became a war-ravaged territory overrun by a subjugated and dispersed population. One reason for these effects was that the East India Company also had many of the characteristics of a modern totalitarian state.

It held absolute and unquestioned authority over the land and peoples of India. Under its appointed officials, it had its own law courts, its own municipal bodies, as well as offices of tax and tariff. It had a military force to resist invasion from outside and to suppress rebellion from within. One of the most astonishingly successful commercial endeavors of all time, it was said to have provided the initial capital by which the Industrial Revolution was launched in England. But it was also, until its dissolution in 1857, a remarkable example of governance wielded through a corporate entity, established for the purpose of stockholder enrichment. The experience of the East India Company would also provide lessons applicable to strategies of global governance, during the twenty first century. 


\section{Modern Progress}

The two legally defined structures, the state and the corporation - both methods for ordering property and persons - would become central institutions in the progress of Western legal development. The Treaty of Westphalia in 1648 marked the symbolic establishment of the nation-state as the sovereign means by which populations and territories would be governed, on the Continent. At the same time, legal scholars at various universities continued to develop the instrument of the corporation. As a subordinate institution intended for purposes of large scale finance and trade, it was especially suited for the modern enterprise, conducted on a broad territorial or maritime basis.

The importance of both legal structures was multiplied, however, by a second wave of technical advance that began early in the nineteenth century, especially innovations that had to do with traversing distance: They included the steamship, railroad, and electronic telegraph. Although these new inventions would not have profound effects equal to those of the fifteenth century, they were even more important in one respect: They would make it possible to extend Western methods of governing, of finance and trade, around the entire world.

Their most tangible effect was to introduce an era of imperial conquest and competition among the Western powers, an unfriendly contest that resulted in the rise of several modern empires. With the new machines it had become possible to not only conquer at great distance, but also to dominate and control. By the end of the nineteen century virtually every remaining unclaimed territory on every distant continent had been annexed, colonized, or at least brought to subjection. In this period of imperial aggrandizement and rivalry, Western methods would be imposed on nearly all regions of the earth. Without the new inventions, such an expansion of influence could not have occurred.

But the inventions had another result as well: they led to a strengthening and consolidation of the already existing nation-states. With rail and telegraph, national polities were able to connect disparate cities and localities. With steam power and transportation they could promote industrial growth. With new mobility and armaments and increased military power they could defend their borders. Perhaps, most of all, by these means of travel and communication they could centralize governing authority. Nonetheless, as dramatic as the impact of the new inventions was, on the empire and on the nation-state, it would be merely a prologue.

The twentieth century became a period of even more rapid technical development, rising to an entirely new level, introducing the automobile, airplane, telephone, and mechanized weaponry. More than that, for the nation-state, especially important were new modes of mass communication: radio and cinema. These electronic methods of broadcast and dissemination, employed in separate languages, made it possible to create a single atmosphere of awareness and understanding within each nation. To an extent never before possible, during the nineteen thirties, an entire population could be united and mobilized for purposes of production and warfare.

\section{A State of Crisis}

During the early twentieth century the nation-state reached the height of its development and, in its various forms, had come to include within its iterations nearly the entire habitable surface of the earth. It was precise in its dimensions, protected by re- 
cognized borders, and entitled to defend itself according to defined rules of war. It was sovereign in its domestic policies, wielding exclusive authority over its people and resources. Each state was recognized as a member of the family of nations, able to enter into relations with any one of its counterparts as an equal polity.

One reason for the successful proliferation of the nation-state, as a form of governance, had been that the stage of technical advancement was well adapted to its limited territorial dimension. During the twentieth century the state had been grounded in welltested doctrines and practice, but it also fit the level of technology prevailing at that time. This included not only the means of transport and trade, but also the printed book and journal in the national language, and, of new importance, radio and cinema - with their astonishing ability to shape public awareness. Combined together, these factors were able to create a total environment of public understanding and national purpose, within a region of common language and custom.

In fact, the ability to mobilize entire national populations for purposes of production and warfare, had brought catastrophic consequences. Because of this, a new international movement had taken shape, to restrain the individual state as a locus of power, and bring it under the authority of an international legal framework. Such a plan was inevitably fraught with complications and resistance, and not only because of deeply rooted animosities between states. There was also lacking an overarching authority, with the power to actually enforce its program of deliberation and cooperation in world affairs.

However, even more fundamental difficulties with the mechanism of the state began to emerge in the late twentieth century, especially with the advent of television and the computer. It is difficult to exaggerate the impact of these two devices on both the national and international level. Sound and image could be broadcast across borders and around the world, penetrating the family domicile in any location on earth. Computerized information of any quantity on any topic could be transmitted from any one location to any other location at any time, by any person. Suddenly, capital could be organized, labor assembled, and resources marshalled, without regard to distance or topography.

For the state, these new developments marked a dramatic challenge not only to its functioning as a territorial authority and to its foundation of national law, but also to its self-sufficiency as a productive entity. Among the first problems to be confronted, was the effective negation of its borders, as a protection against unregulated communication and trade. The former conception of the border as an absolute and defined barrier separating not only territories, but also legal jurisdictions, was becoming untenable. Overseeing the affairs of its own citizens had been rather easy, because both they and their property generally existed within the region marked by national borders. Matters were less simple with those entities whose primary assets and ownership lay outside territorial limits, and beyond the reach of authority.

But the impact of these technical innovations proved, once again, to be simply a prelude to what would come. The approach of the twenty first century marked not only the advent of a new millennium, but also the onset of a new age. It was termed the age of technology, of information, and of globalization. It was sometimes referred to as the postmodern age to distinguish it from the period of modernity that preceded it. In 
fact, because of remarkable advances in technology - and the way it was employedmany conventional forms of governance and rule were coming to be reconsidered and displaced. In particular, the nation-state seemed to be undergoing a profound decline and regression.

\section{The Rising Corporation}

As the new millennium approached, the problems roiling the state were being more than offset by the exhilarating impact the new technologies were having on the corporation. For that legal construct, electronic transmission of sound and image, telephonic communication, information systems, and computerization were unqualified positives. A proliferation of computer networks around the world, reached into the most remote and inaccessible regions. Worldwide television broadcasting brought enormous commercial opportunity with its combination of entertainment and advertising. The new ability to travel, to transport, and to trade, to reach a world market of entire populations, opened unheard of opportunities for expansion and consolidation.

These technical advances accelerated even more the expansion of decentralized multi-national corporations, strengthening their ability to manage and control. From the perspective of Anglophone governance, certain advantages of the corporation over the state were also becoming obvious. Moreover, the influence of technical applications had begun to blur the old divisions between corporation and state, public and private, economic and political. But for Anglophone legal practice, this posed no special difficulty, because, in its view, both the state and the corporation were equally subject to oversight by collegial adjudication. Beyond that, for the purpose of giving force to the directives of an elevated legal authority, each had advantages particular to itself.

From the seventeenth century, in the Anglophone realm, the corporation had been a highly favored means of extending legal authority. Compared to the state, it was less bound by statutory obstacles, as well as the impediment of constitutional questions and political meddling, and it could be utterly pragmatic in its operations. Corporate proprietors, with their unchecked oversight, generally operated outside of view, not directly accountable to the public. Most of all, the corporate ability to adapt pragmatically to change was perhaps the great key to its usefulness. For purposes of ordering human action and shaping human thought, the advantages of the corporation over the state were many.

From this perspective, an entirely new overarching legal regime, anchored less in the state and more in the corporation, was also possible. The non-territorial corporation was able to extend its operations without geographic limit. Even if nearly two hundred territorial states covered the earth, a single modern corporation could cover the same territories-easily transcending state jurisdictions, its extensiveness unimpeded by any national border. It was the natural vehicle for strategies of Economic Development, Open Markets, Interdependency, and Free Trade. Viewed in a certain way, these terms were very often, in fact, merely inverted ways to explain the process of corporatizing the properties and persons of various overseas countries.

But there were other advantages as well: for example, through the instrument of the corporation, legal jurisdictions might reach far beyond national boundaries. It offered 
a solution for those situations, in which the authority of one state was prohibited from reaching across its national border into the territory of another state. The corporation could provide, in effect, an extraterritorial reach from one legal regime into the domestic affairs of another. With the new technical abilities, the corporation could provide all the necessary provisions and resources for the feeding and clothing of populations. It might provide a military presence in the form of weapons, strategic advice, and in extreme circumstances, even mercenary soldiers.

In the past, the role of education had fallen to the state. But with the new advances, nothing could equal the various electronic media as instruments for shaping public behavior, norms, and values. The corporation was able to provide an atmosphere for understanding political and world affairs, information the public needed to acclimate and participate in a worldwide regimen of governance. Unlike the old brick and mortar national school system, with its instilled ideology, and its laborious method of rote learning, the new media could create an atmosphere of understanding that was continuous and ubiquitous in its effects, and required little effort on the part of the learner. Nothing could match this potential ability to instill habits of acceptance and compliance, a crucial necessity for an established Rule of Law.

From the perspective of English legality, all of these factors served to blur the artificial dichotomy of public and private, political and economic, national and international. A perhaps irresistible challenge to the existing state system of the world had arisen; it was technologically based, and fully compliant with requirements of law, because it was legal in its composition. In fact, in the case of Anglophone legal practice, the converging elements of technology, state, and corporation allowed a kind of reversion to its primitive, more essential form as a medieval fellowship.

The Common law was based on a guild model, that had long pre-existed both state and corporation, and it came from a realm quite distinct from theirs. It was an organic fellowship of members, neither an abstract construction nor an articulated system - it was founded in a bond between persons. From its collegial perspective, both political and economic institutions could be equally useful beneath the independent sovereignty of a judicial hierarchy. Viewed pragmatically, both structures might be employed to form a legal culture. All that was needed to bring this enveloping tandem of legality into being was a coercive means of enforcement.

\section{Hegemony}

An undisputed Anglophone world predominance first arose during the nineteenth century of the Pax Britannica. No nation or group of nations could match the industrial, financial, and naval power of the British Empire. In the twentieth century, following the two great worldwide wars, the groundwork of Anglophone predominance was established once again, but on a different basis; it rested primarily on the Atlantic alliance between Britain and America. In conflicts that had left much of the world in rubble, the combined strength of the English-speaking nations had only been increased. Especially, after the worldwide war of the mid-century, their industrial and military capacities had been virtually untouched, and both were operating at peak efficiency. 
Traditionally, the hallmark of Anglophone influence in the affairs of the world had been the Balance of Power. This strategy was especially effective when employed against the Continental states. Europe, after all, was a patchwork of small and large nations, divided by language, culture, and religion. Fomenting hostilities between any two of them was often rather easy. Britain normally sided with the weaker of two protagonists, keeping Europe perpetually on the brink of conflict. In the generation following the second great war, in fact, the entire world had come to be divided into such a balance: the Cold War, a stalemate of crisis and provocation, between Russia and the United States.

During this period the Anglophone alliance, united by a common legal heritage, would continue to enlarge its already enormous corporate, media, and military influence. It combined British diplomatic sophistication going back centuries, with almost limitless natural resources, dispersed around the world. The combined financial, commercial, and industrial power, together with its far-reaching system of marketing and management, produced an irresistible force - what in the nineteen seventies was frequently condemned as Anglo-Saxon capitalism.

However, after the collapse of the Soviet Union in the last decade of the twentieth century, there existed, once again, the unusual situation of a single power predominant in world affairs. That great world power was, of course, the United State - but it seldom needed to act entirely alone. Invariably it moved in partnership with its more sophisticated British mentor. Beyond Britain, the U.S. had an inherent kinship with all the other countries and polities that shared in the Common law heritage: Canada, Australia, New Zealand, as well as Singapore, Hong Kong, and Israel. Out of public view these partners also asserted a broad underlying legal influence in world affairs. In the aggregate, this influence and its various permutations amounted to the skeletal basis for an alternative system of world order.

The Europeans, of course, had already begun their experiment in building a unity of nations within a geographic region of shared history and culture. It was being assembled, quite naturally, on the explicit principles of reason and universalism that typified its Civil law traditions. In this undertaking, the sovereign state was subsumed within the outlines of a unity, having some of the properties of a confederation. The European Union was able to assimilate elements of statehood into a larger collective, because the new technical advances made this possible. The project was limited to Europe - with the inclusion of anomalous Britain - but the hope was that it might provide an example for the consolidation of other geographic and cultural regions around the world.

From the perspective of Anglophone legality, the European approach, as a basis of world order, was more problematic than helpful. It was, after all, premised on the state. Moreover, even though it offered a wide allowance for recognizing and assimilating the many cultures and religions within a region of states, the Anglophone approach could do more. In the vacuum of power left by the collapse of Russia, the English fellowship had seen an opportunity to piece together the elements of a seamless world order, on a different basis. Their approach could be carried out in a way that would include all regions around the world in a single regimen, precisely because it was indifferent to any particular cultural, religious, or ethnic composition. 
To affect such a regime, across every nation and people, the initial requirement was a worldwide mechanism of enforcement, wielding coercive power, not only over individuals and institutions, but also over the various nation-states. This cumulative force could be asserted, benignly, in the form of diplomatic persuasion. Toward more recalcitrant polities, the device of economic reprisal could be employed. Finally, in the most extreme cases, military force was the ultimate means of unquestioned dominance. With the new technologies of warfare, the Anglophone nations could intervene immediately, efficiently, and at any location on earth.

Yet, experience showed that for any regime, including a hegemonic power, the instrument of brute force alone, as a means of rule, is only useful in the short term. Ultimately, for purposes of governance on a global scale, a very substantial legal and commercial foundation must be combined with extensive channels of public acculturation and education. This would include ties of material interdependency, contract, treaty, judicial accountability, policing authority, institutions of learning, and electronic media. In effect, a wholly functioning, immersive reality, an enveloping frame of global legal culture, that would overlay the system of bordered states. In the Anglophone approach this required one more element: a universal understanding and use of the English language.

\section{The Universal Language}

Among the unique features of the aged Common law tradition, including its collegiality, its esoteric complexity, and its oracular judiciary, one factor remained constant as the single essential of its operation: all its unique attributes required that its members use the same language. The collegial nature of the English law - its bond of personal familiarity, its attachments of common experience, its loyalties, its disputatious methods of trial, and its hierarchy of judicial obeisance - could operate in no other way. Beginning in the nineteenth century the Common law had begun to take effect in countries around the entire world, but only among those where English was employed with fluency.

Since its inception in the eleventh century its method of legal rule relied on two modes of communication. During its earliest medieval stages, when printed documents and the ability to read were exceptional, its procedures and methods relied almost entirely on the spoken word - beginning with the oath of admission to the guild. But its internal directives were hand written, and after the onset of printing and the wider use of printed charters and ordinances in the seventeenth century, written expressions of legal authority became more important. Also, public education in the legal culture came to be more reliant on the printed book. In the history of Common law, although both media were important, fundamentally, the collegial aspect of the tradition was personal in nature, and the spoken word, person to person, face to face, among its fellows was basic to its nature - but as a continuing judicial presence, the guild was anchored in the written or printed text.

The Anglophone approach to global adjudication would not necessarily require establishing a fixed structure, or set of principles - and, especially, not a structure resembling some kind of world state. Instead, in the English pattern of legal rule, governance would consist of a collegial and organic plenitude of authority. It might include associa- 
tions, firms, partnerships, initiatives, societies, clubs, associations, and schools. Rather than a clearly defined federation of states, or a clearly defined structure of political administration on the model of the Civil law, it would comprise a much less explicit form of cohesiveness. The presiding edifice of legal rule would amount to obligations and opportunities, within a transcendent collegium joined by common language.

However, the English legal tradition had, from its origins, been constructed on a hierarchical or graded ladder of rank and status. This was most apparent in relations between the privileges of the lawyer as compared with the rights of the subject. But also, within the legal caste itself, there were differences of rank, and certain of those differences were given effect by the way in which language was used. These distinctions had been important since the nineteenth century, because the British not only attempted to build a world empire, they also attempted to retain within it the familiar ranks and grades of a medieval hierarchy.

In particular, there were two levels of the English language, what might be called the rhetorical and the common, or the aristocratic and the plain. During the nineteenth century, when Anglophone law was propagated to all the English-speaking world, styles of speech separated gradients of rank, between the classes within England, but also between the English and the Colonial populations. Most of all, there was a division of speech, between those within the Empire, and those outside it, especially the Americans. The manner and quality of speech had always been an immediate indicator of class and distinction. Language was an instrument of rule in several ways, and was not only important as a bond between legal fellows, but also as a means of marking difference and distance between fellows.

The rise of English to the status of a universal language began to occur during the first decades of radio broadcast, especially in the nineteen twenties and thirties. With the victory of the English-speaking peoples following both great wars, the advantage in commerce and communication made the English language, almost by default, the world language of both finance and trade, even encroaching on the domain of French, as the language of diplomacy. But the great leap in the extent of English fluency around the world, came with the onset of the technological revolution that was underway in the late twentieth century.

There was only one superpower in the world, America, its values, appetites, and amusements were broadcast virtually everywhere. Suddenly, a rising generation was immersed in an atmosphere of transmitted sound and image, almost an alternative reality. Along with that, the availability of information by way of computer, followed by the advent of computer networks was another great step. Because, the initiative of technical transformation was so much in the hands of the English-speaking world-especially America - quite naturally, much of this electronic errata was broadcast, stored, and transmitted in the English language.

To construct a regimen of legal rule requires that both those who rule and those who are ruled over, understand each other, and to a minimal extent, that means they must speak the same language. Anglophone law can only become manifest among practitioners who speak English fluently, and among a population that can, at least to a basic 
level, understand it as well. Although the importance of the language began as the basis of its legal practice, it was equally important in the other half of the legal culture: shaping the thought and habits, the appetites and aspirations of the public. The possibility of a global Anglophone legal culture began to emerge when English had become a technologically transmitted global language - on both a professional and a public level.

\section{Globalization}

There are many ways to understand the project of globalization as it is being advanced to include all localities and all peoples of the world. But no way of understanding is complete without including the foundation of legality on which it is being constructed. That foundation will include the same basic elements that have been employed for nearly a thousand years: an adjudicative method that brings order to human life, coupled with an educative method that gives shape to human thought. Together, the two elements, coercive and persuasive, will form a global legal culture. Anglophone law, in its efforts to construct such a Rule of Law, approaches the project in a characteristic manner. But with advancing technical abilities, it is able to extend both its authority and shape public understanding in a new way and on a far wider scale.

Historically, the Anglophone law, both in its domestic application, and while enlarging its influence through the realm of world affairs, has followed a consistent pattern. That pattern corresponds to three fundamental elements of its makeup. First, the approach is collegial, not structural; it is bound by pledge, and although it employs institutions, it is not, itself, institutional. Second, its fundamental nature is based on the incentive of profit for its members, and with that the encouragement of wealth production generally, to maximize the opportunity of those members. Finally, the English legal method is independent. That is, both the fellowship of practitioners and its hierarchy of jurists, act as an elevated and detached presence. In this respect, they follow on the omnipotent High Court of Parliament; their jurisdiction is without limit, and they recognize no authority superior to themselves.

However, in and of itself, the Anglophone fellowship of law would not be capable of extending its rule on a global scale. To accomplish this great objective it must rely on other subordinate and subsidiary agencies and institutions. Of primary importance among these is the fixed territorial structure of the state. This construct is especially useful as a regulatory body and as a basis for civil order among the separate national populations. The other structure of especial importance is the corporation, with its flexible adaptability and veiled autonomy. Together, this tandem of highly developed legal constructs provides mechanisms adaptable to the many requirements of global governance.

Yet, such advances on a global scale would not be possible without the remarkable progress of technology. Just as during the sixteenth century, the period of the three great inventions-gunpowder weapons, maritime compass, and printing press - tools and devices have made possible unprecedented concentrations of power and wealth. During that early period these concentrations were manifest in the nation-state, on the Continent, and Parliamentary rule in England. Later, in the nineteenth century, new innovations - steamship, railroad, and telegraph - provided the means by which empires could be constructed and ruled. One result was the rise of great imperial powers, culminating, 
especially, in the British Empire that once included nearly a quarter of the land surface of the earth. Most importantly, by means of these inventions, Western methods of governance, of finance and trade, were imposed on virtually all parts of the world.

However, the Anglophone method of global governance during the twenty first century will not precisely replicate the methods of the eleventh century, the seventeenth century, the nineteenth century, or even the twentieth century. This is especially true in the educative, or persuasive, aspect of its rule. The old nation-state, was precisely adapted to the printing press, book, and journal, as a means of shaping the public mind, instilling a fixed structure of belief. But now there are much more highly evolved channels and networks for shaping human consciousness - not by instilled belief, but by a continuous flow of information. The ability to construct, in effect, a virtual reality of transmitted sound and image, provides entirely new possibilities for creating an atmosphere of public acceptance and compliance. Moreover, these methods are easily adaptable to all regions and peoples of the earth.

When examining the Anglophone alliance and its globalization project, several impressive achievements become obvious. Not only does it have enormous hegemonic power to advance its method, it also has pragmatic flexibility to establish a transcendent authority. By its collegial approach it can adapt to changing circumstance with agility, even absorbing and employing the concepts and methods of Civil law. In the process it need only retain two essentials: one is the cohesion of its membership, beneath the authority of its judges around the world; second is the willing compliance of all those peoples subject to its authority. With advanced technology, it is possible to marshal the many instruments of legal order, including both state and corporation, to advance this collegial purpose. By these varied means, an Anglophone legal culture can be developed, and by these means its global Rule of Law can be established.

\section{READING ON THE TOPIC}

Arnold, M. 2006. Culture and Anarchy. Oxford: Oxford University Press.

Breyer, S. 2015. The Court and the World. New York: Knopf.

Bryce, J. 2015. The Ancient Roman Empire and the British Empire in India. Forgotten Books.

Buzan, B. 2006. From International to World Society. Cambridge University Press.

Coase, R. H. 1990. The Firm, the Market, and the Law. Chicago: University of Chicago Press.

Conley, T. 1994. Rhetoric in the European Tradition. Chicago: University of Chicago Press. Cosgrove, R. 1987. Our Lady the Common Law. New York: New York University Press.

Dicey, A.V. 1989. Introduction to the Study of the Law of the Constitution. Indianapolis: Liberty Fund.

Dworkin, R. 1986. Law's Empire, Harvard.

Goldstein, J. 2001. Legalization and World Politics. Cambridge, MA: MIT Press.

Gorski, P. 2003. Disciplinary Revolution: Calvinism and the Rise of the State. Chicago: University of Chicago Press.

Habermas, J. 2008. Europe, the Faltering Project. Cambridge: Polity Press. 
Habermas, J. 2008. The Divided West. Cambridge: Polity Press.

Jackson, J. 1998. World Trade Organization Constitution and Jurisprudence. Chatham House Papers. London: Royal Institute of International Affairs. .

Joerges, Ch. 2005. The Economy as Polity. London: UCL Press.

Lambropoulos, V. 1993. The Rise of Eurocentrism. Princeton, N.J.: Princeton University Press.

Micklethwait, J. 2003. The Company: A Short History of a Revolutionary Idea. Modern Library Chronicles.

Nelson, E. 2010. The Hebrew Republic. Cambridge, MA: Harvard University Press.

Ong, W. 1988. Orality and Literacy. The Technologizing of the World. London: Routledge. Slaughter, A.-M. 2004. A New World Order. Princeton: Princeton University Press.

Tiger, M. 1977. Law and the Rise of Capitalism. New York: Monthly Review.

Watson, A. 2009. The Evolution of International Society. London: Routledge.

Williams, R. 1983. Culture and Society. New York: Columbia University Press. 